\begin{abstract}
The Next Generation Air Transportation System (NextGen) and Europe's Single European Sky ATM Research (SESAR) concepts require an increased use of trajectory-based operations, including extensive strategic air traffic control clearances. The clearances are lengthy and complex, which necessitates data link communications to allow for message permanence and integration into the autoflight systems (i.e., "autoload" capability). This paper examines the use of flight deck data link communications for strategic and tactical clearance usage in the terminal area. A humanin-the-loop simulation was conducted using a high-fidelity flight deck simulator, with ten commercial flight crews as participants. Data were collected from six flight scenarios in the San Francisco terminal airspace. The variables of interest were ATC message

modality (voice v. data link), temporal quality of the message (tactical v. strategic) and message length. Dependent variables were message response times, communication clarifications, communication-related errors, and pilot workload. Response time results were longer in data link compared to voice, a finding that has been consistently revealed in a number of other simulations [1]. In addition, strategic clearances and longer messages resulted in a greater number of clarifications and errors, suggesting an increase in uncertainty of message interpretation for the flight crews when compared to tactical clearances. The implications for strategic and compound clearance usage in NextGen and SESAR are discussed.
\end{abstract}


Tenth USA/Europe Air Traffic Management Research and Development Seminar (ATM2013)

\section{An Investigation of Flight Deck Data Link in the Terminal Area}

\author{
Lynne Martin \\ San Jose State University \\ NASA Ames Research Center \\ Moffett Field CA, USA \\ Lynne.H.Martin@nasa.gov \\ Vicki Dulchinos \\ San Jose State University \\ NASA Ames Research Center \\ Moffett Field CA, USA \\ Victoria.L.Dulchinos@nasa.gov
}

\author{
Sandra Lozito \& John Kaneshige \\ NASA Ames Research Center \\ Moffett Field CA, USA \\ Sandra.C.Lozito@nasa.gov \\ John.T.Kaneshige@nasa.gov \\ Shivanjli Sharma \\ SGT Technologies \\ NASA Ames Research Center \\ Moffett Field CA, USA \\ Shivanjli.Sharma-1@nasa.gov
}

\begin{abstract}
The Next Generation Air Transportation System (NextGen) and Europe's Single European Sky ATM Research (SESAR) concepts require an increased use of trajectory-based operations, including extensive strategic air traffic control clearances. The clearances can be lengthy and complex, which necessitates data link communications to allow for message permanence and integration into the autoflight systems (i.e., "autoload" capability). This paper examines the use of flight deck data link communications for strategic and tactical clearance usage in the terminal area. A human-in-the-loop simulation was conducted using a high-fidelity flight deck simulator, with ten commercial flight crews as participants. Data were collected from six flight scenarios in the San Francisco terminal airspace. The variables of interest were ATC message modality (voice $v$. data link), temporal aspect of the message (tactical v. strategic) and message length. Dependent variables were message response times, communication clarifications, communication-related errors, and pilot workload. Response time results were longer in data link compared to voice, a finding that has been consistently revealed in a number of other simulations [1]. In addition, strategic clearances and longer messages resulted in a greater number of clarifications and errors, suggesting an increase in uncertainty of message interpretation for the flight crews when compared to tactical clearances. The implications for strategic and compound clearance usage in NextGen and SESAR are discussed.
\end{abstract}

Keywords - data link communications; terminal airspace operations

\section{INTRODUCTION}

The use of data link (also known as DataComm) for clearance data is considered essential for Next Generation Air Transportation System (NextGen) and Europe's Single European Sky ATM Research (SESAR) operations due to the requirement for strategic messages that contain lengthy and complex data $[2,3]$. Since data link provides an opportunity for a more permanent representation of data, the memory requirements associated with the vast quantities of numbers and text, such as those represented in a long route clearance, are alleviated [4]. In addition, data link offers the ability to directly enter clearance data into the relevant autoflight systems ("autoload"), thereby reducing the opportunity for pilot input errors. Previous research suggests that the use of the autoload function in data link reduces pilot data entry time and may reduce pilot errors [5].

The focus upon trajectory-based operations in the NextGen and SESAR concepts creates a stronger requirement for the use of data link in the terminal airspace. The need for complex routing information exchange will promote clearances that are more strategic in nature. In today's operational environment, there are concerns with the use of the current day flight deck data link in the terminal area. The Flight Management System (FMS)/Control Display Units (CDUs) are located near the center console, which requires pilots to direct visual attention away from other critical flight data. In addition, the increased response times typical for data link may be problematic in the terminal area where the proximity to the airport and other aircraft require very timely air-ground communications, as well as clearances to refine aircraft trajectories as they are configured for landing. On the other hand, data link reduces frequency congestion and alleviates pilot memory constraints, which may reduce pilot and controller workload and flight deck errors [10]. Additionally, the autoload function is expected to reduce data entry errors [11]. Thus far, there have been relatively few studies examining the role of data link within the terminal area. 
Although the timeliness of clearance response is always important for ATC operations, the increased congestion and proximity to the airport represented by the terminal area makes message response time even more critical. Despite the lack of experimental guidance on data link use in terminal operations, SESAR and NextGen have operational procedures intended for implementation in the terminal area, such as continuous descent arrivals, spacing and sequencing procedures, and closely-spaced parallel runway operations. Many of these applications are already occurring in a number of areas within the US, Europe, and other parts of the world. The exchange of data required for these operations will continue to require the use of transfer of data through digital means. Further research is necessary to explore the potential concerns and benefits of using existing data link technology and procedures in terminal airspace operations.

This study examined the use of flight deck data link and voice clearances in the San Francisco Airport (SFO) terminal area in a human-in-the loop simulation. The variables of interest were clearance modality, message length and the use of strategic and tactical clearances. The impact of these variables upon communication efficiency, as an indication of situation awareness, was examined.

The paper is organized as follows. Section II provides background about the use of data link communications. Section III describes the experimental details of the simulation. Results from the simulation are discussed in Section IV. Lastly, Section V concludes with a summary of key findings and plans for further research.

\section{BACKGROUND: DATA LINK COMMUNICATIONS}

In today's environment, data link communications have become more broadly used for digital transfer of Air Traffic Control (ATC) clearances in a number of international airspaces, primarily as a means to address communication availability and inefficiency in oceanic airspace and to address voice frequency congestion. Controller-Pilot Data Link Communications (CPDLC) have been operational at the Maastricht Upper Area Control Center (EDYY) for over a decade, reporting the use of CPDLC data link messages by over 30 different airlines in 2008 [12]. Further data link applications are expected as part of Europe's Link 2000 program. Future Air Navigation System 1/A (FANS 1/A) data link communication has been in use in trans-oceanic flights for over 15 years. There are various forms of data link in operation today, including airline operations messages, air traffic services, and pre-departure clearances.
Previous studies have found that message acknowledgment times are often longer in data link communications when compared to voice [1] due to interface constraints. These studies used a variety of data link implementations, each with their own interface constraints, although most of the implementations involved a visual, textual data link. Crew procedures have also been found to have an important impact upon data link message handling and its efficiency [6]. Research also suggests that introducing other data link implementations, such as the use of more graphical displays or procedural changes may also reduce the data link response time variability by providing more succinct means of evaluating the clearance data [7].

The use of data link communications in current day operations relies upon a textual-based flight deck interface for data link. The Future Air Navigation System (FANS) on the Boeing 747-400 is an example of an existing flight deck device that allows current-day Data link in the oceanic environment, using the onboard FMS/CDU. Although these operations are generally considered successful, it is known that integrated FMS and data link cannot fully replace voice communications using current day procedures [6]. Data link and voice are fundamentally different in terms of human performance, flight deck tasks, and procedures, offering different strengths and weaknesses to the operator and the system [8]. In addition, the use of data link requires relevant technology for both the air traffic control and flight deck environment. Thus, it is anticipated that the combination of voice and data link will exist for the foreseeable future. Voice and data link communications have different procedural constraints. Research findings have shown an increase in accuracy and consistency for data link at the cost of speed for the transfer of information [1]. Combining the data link and voice media in a mixed environment may alter their characteristics in a way that does not maintain the advantages of each medium separately. Results from a previous simulation indicated that voice transaction times were longer in the mixed than in the single medium environment, while data link transaction times were unaffected by the environment [9].

Human factors research has attempted to match the growth of the operational use of data link communications by investigating the benefits and concerns of this information exchange method upon the human operators (pilots and controllers). The flight deck studies have examined the use of different implementations of data link across a number of flight phases. Several data link simulations in the US and Europe were conducted in the oceanic and en route flight phase, where data link has been most prevalent in the current 
ATM operations [1]. A few studies have explored the use of data link for taxiing instructions as part of surface operations $[13,14]$. In most cases, the research has revealed that data link communications have resulted in longer message acknowledgment times.

\section{METHODS}

This study was designed to assess the effects of communication medium (voice and data link), message length (short and long), and message temporal aspect (strategic or tactical) on acknowledgment times and communication inefficiency (clarifications and errors). In addition, the impact of the data link autoload capability was explored. The effects of message content type (route, speed, altitude, frequency change) will be discussed in future papers.

\section{A. Participants}

Twenty airline pilots participated as flight crewmembers. Captains and First officers from the same carrier participated as the same flight crew during the simulation. All participants were either currently flying or retired for less than one year and type-certified on the Boeing 747-400. Average total flight time for the participants on FMS-equipped aircraft was 9617 hours, and the average time using data link communications was 10 years.

\section{B. Simulation Facilities}

Crews flew in the Boeing 747-400 simulator at the CrewVehicle Systems Research Facility at the NASA Ames Research Center. This NASA simulator was built by CAE Electronics and is certified to the FAA Level D certification requirements [15]. An ATC simulation environment was also used that allowed the confederate controller to communicate with the pilots for the scripted voice messages and to allow for addressing queries from the participant crews.

\section{Flight Scenarios}

The six scenarios flown by the participant crews consisted of three different routes into the San Francisco International Airport (SFO): the BigSur, Modesto, and Oceanic routes. Fig. 1 is a depiction of the three routes that were flown by the pilot participants. These arrival routes are all current routes into SFO, but were modified slightly from the original standard arrival routes to allow for new procedures into the airport. The routes started several minutes before the top-ofdescent, and took about 35 minutes to fly. The order of the routes were mixed for the different crews. In addition, each of the three routes were flown two times: once with the ability to autoload a subset of the data link clearances within the scenario, and once with those same clearances provided but without the ability to autoload the clearances.

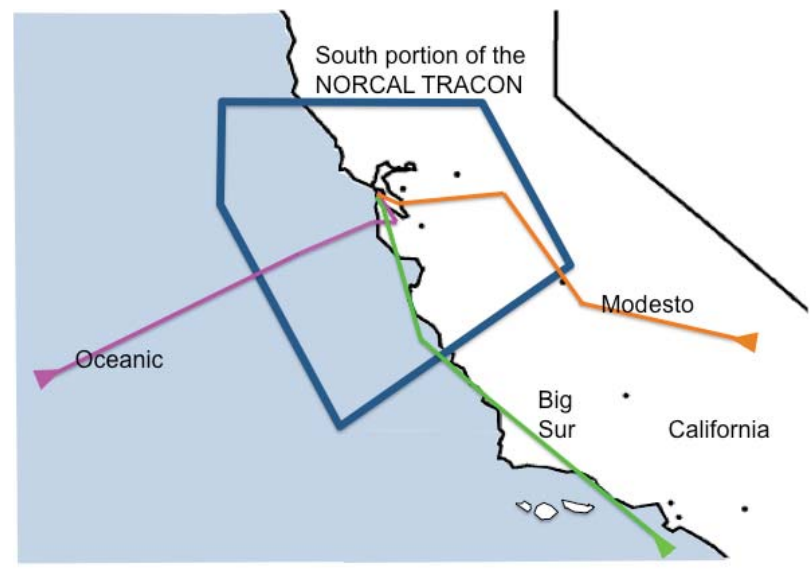

Figure 1. Big Sur, Modesto, and Oceanic Routes. Dots indicate locations of major airports.

\section{Data Link Functionality}

The simulator was equipped with FANS 1/A data link as it exists on the Boeing 747-400. This is a Flight Management Computer (FMC)-integrated data link utilizing either of the forward CDUs as an interface. Fig. 2 is a picture of a data link message on the FMC/CDU. An ATC function key on the CDU keyboard allowed both crewmembers access to the ATC data link information on their respective CDUs. Each of the forward CDUs can also be used to interact with the FMC for data input or output (e.g., altitude, route, or speed data).

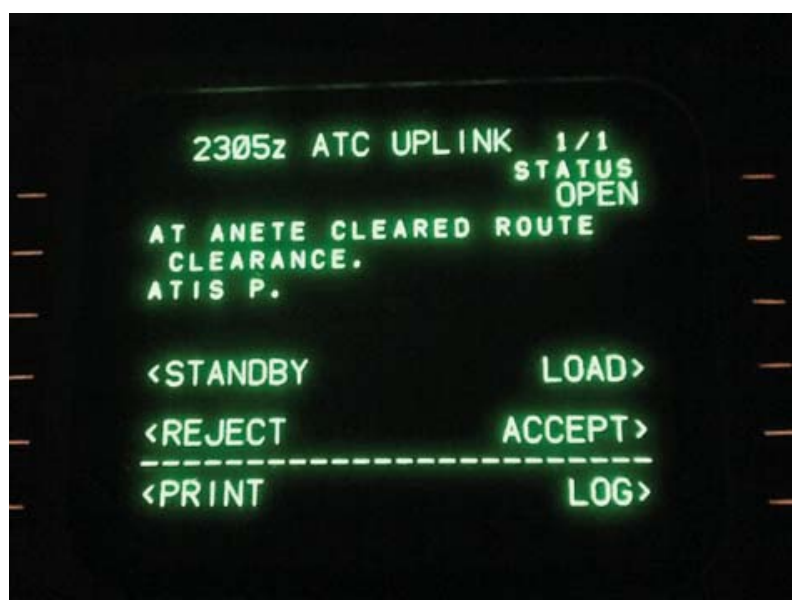

Figure 2. Picture of the FMC/CDU with a data link message

Upon receipt of a data link message, the visual alert and aural alert notified the crew of the presence of a message. An ATC function key was used to access a new message. Once a message was accessed, it was displayed on the CDU. The message page consisted of the message content, the text ATC UPLINK at the top, a time stamp representing the time a 
message was sent, and a page number. In addition, the message acknowledgment options were displayed at the bottom of the message, which included "ACCEPT" and "REJECT".

For a limited number of clearances, there was also a "LOAD" prompt, which enabled the direct entry of the message contents into the FMC. This prompt was not available for all the clearances, but was available for a subset of clearances with route information.

\section{E. Instructions and Training}

Before flying the simulator, participants were given an overview of the experiment. They were told that the focus of the study was on air-ground communication in different experimental conditions. Although all participants were experienced in using FANS 1/A, they participated in a short briefing and training on the data link system. The briefing included a discussion about data link crew procedures. Since all the flight crew participants were from airlines that currently use oceanic data link, crews were asked to use their own company procedures to handle a data link message. These procedures primarily fell into two categories. One of these procedures involved having the Pilot Monitoring, who normally handles communication, read the message aloud and wait for some verbal confirmation from the Pilot Flying prior to acknowledging the message. The second airline data link procedure was one in which the Pilot Monitoring printed the message, and each crewmember silently read the printed message. They then discussed the message and the Pilot Monitoring acknowledged it. After the briefing, the crews participated in a short 30-minute training scenario, in which the crews flew the simulator and operated the data link communications.

\section{F. Procedure}

For the six short flight segments into the San Francisco terminal area that each crew flew, pilot participants alternated their roles as Pilot Flying and Pilot Monitoring for each flight leg. Each flight leg was comprised of approximately 16 ATC clearances that contained a mix of voice and data link messages to represent realistic flight operations. All data link messages were from the RTCA Data Comm message set that was current at the time of the investigation [16]. During the study, a retired Terminal Radar Approach Control (TRACON) controller was available to relay the scripted voice messages and to respond to any pilot communication. These clearances were represented in both the data link and voice modality across runs, to allow comparisons of the two when examining response times and clarification and errors.
The ability to autoload route clearance data was also a variable in this simulation. There were a limited number of clearances in which at least one element of the clearances could be autoloaded into the autoflight system. This clearance function was derived from the existing RTCA message set currently in use. That message set and the aircraft avionics constrain the autoload function; therefore, the ability to represent this in our simulation was limited by the aircraft capability. In half of the scenarios the crews had an ability to autoload some ATC clearances, while in the other half they had to manually load those same clearances.

The study included a number of strategic clearances intended to reflect routing instructions that represent both NextGen and SESAR operations. Examples of those clearances included the following: "At BOLDR proceed direct CEDES, Cross BOLDR at and maintain 10,000 feet" and "Proceed direct to MEHTA Cross MEHTA at or above 6000 ft. Cleared ILS runway 28 Right Approach". One half (about 8 out of 16) of the clearances within each scenario were strategic. The remaining clearances within a given scenario were tactical clearances, such as "Reduce speed to 180 ". The lengths of messages were also varied to compare the effects of long versus short messages on memory and crew uncertainty. A third of the messages given to crews were "short", with one element to the clearance. Approximately $40 \%$ of the messages were "long", containing three to four elements in the clearance. The remainder of the messages were frequency changes (which contained two elements if they were presented through data link and only one if they were delivered via voice).

In order to simulate a full breadth of data link clearance types and to prevent familiarity effects, the modality mix of the clearances was manipulated based upon message content type. If a message was primarily based upon an altitude or frequency change, then those messages were represented in three of six scenarios in data link and in the remaining three scenarios in the voice modality. Similarly, routing and speed instructions were manipulated as being represented in one half of the scenarios in voice and the other half in the data link modality.

\section{RESULTS/DISCUSSION}

\section{A. Acknowledgment Time}

Message response time was analyzed to examine differences between voice and data link acknowledgment times. For the voice condition, response time was defined as the time at which the controller begins relaying the clearance to when the pilot completes his/her readback. If clarifications 
are required during the response, those clarifications extend the response time until the pilot has completed the readback correctly. For data link messages, the measure of the response time starts when the Air Traffic Controller hits the "send" button on his data link interface, and is considered complete when a pilot has completed the interface steps for accepting the message and the ATC receives the down-linked response, or has received the pilots' acceptance via voice. These response time calculations are consistent with previous research calculations $[9,16]$.

Data link acknowledgment times were found to be significantly longer than voice times $(t=18.0, \mathrm{df}=792, \mathrm{p}<.001)$ The average acknowledgment time for voice was $4.0 \mathrm{~s}$ (standard deviation $=13.7 \mathrm{~s}$ ), while for data link the mean was $34.2 \mathrm{~s}$ ( standard deviation $=17.9 \mathrm{~s}$ ) (Figure 3 ). In addition, when comparing data link response between instructions that could be autoloaded into the autoflight system, with those that were not loadable, messages that were autoloadable had significantly longer response times than manual messages $(\mathrm{F}=6.71, \mathrm{df}=2,440, \mathrm{p}<.001)$.

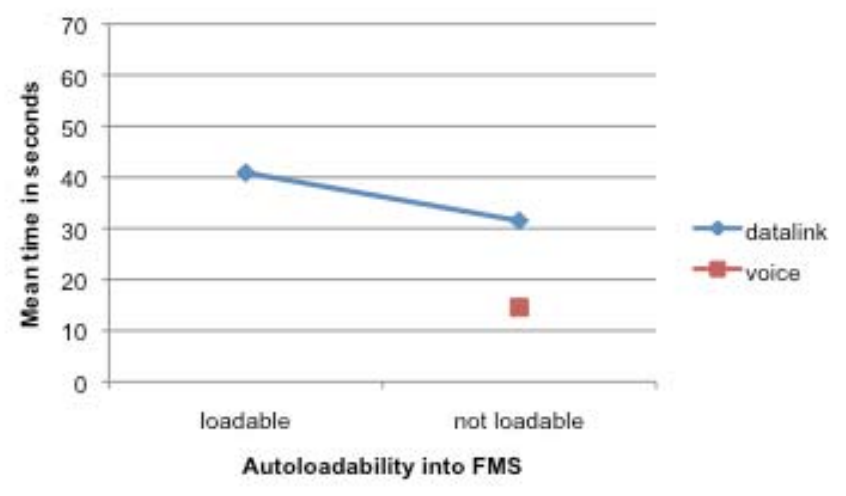

Figure 3. Message response times for communication modes and loadable and not loadable capability

The acknowledgment times are directly related to the interface used for the digital communications. The data link implementation used in this study requires the time-sharing of the $\mathrm{FMC} / \mathrm{CDU}$, and therefore depends upon the alerting scheme to notify the crew of the presence of a message. In addition, message access and response requires interface steps within the CDU that result in additional time for message response.

These results are consistent with a number of other studies comparing voice to data link clearances $[1,7]$. Although current operations suggest that timely clearance response time is essential, particularly in the terminal area, it is unclear what the specific timing constraints are for ATC clearance response.
In post-simulation questionnaires and debrief comments, most of the pilot participants felt that the use of data link in the terminal area was acceptable, noting the reduction of memory constraints that exist with the permanence of the message.

A somewhat surprising finding was the longer response times for autoloadable data link messages compared to those that could not be autoloaded. Clearances with this capability were those associated with route data, which represents the same autoload function that exists in the current FANS 1/A package on the Boeing 747-400 aircraft. This result appears counterintuitive, since data entry time is reduced when the using the autoload function. Other data link investigations have found a reduction in crew acknowledgment time associated with the autoload capability. One possibility for the current results is that due to additional reliance upon flight deck automation, the autoload function may compel some crews to conduct additional scrutiny of the impact of the data entry. Previous research has found that crews may be less likely to detect erroneous clearance elements when autoloading data link messages as compared to manually loading data [5]. Moreover, in many clearances not all the message elements were autoloadable. Consequently, due to this added complexity, there was an increase in time to process exactly which elements were loadable in each individual clearance.

As operations shift to SESAR and NextGEN, the intent of these future concepts is to have a reduction in clearance instructions in the terminal area. More air-ground data exchange should occur further away from the airport, enabling more complex trajectory data and involving more automation. It is certain that clearance negotiations will still be necessary in the terminal area, but the exact role of the pilot response will change as more reliance upon automation is used more often for clearance data exchange and implementation.

\section{B. Communication Clarifications and Errors}

Clarifications and errors were analyzed as a means of examining potential confusion associated with the clearances data. A clarification was defined as a query related to the content of an ATC message between the pilots or between a pilot and the controller, e.g., "what speed did we get?" An error was defined as an erroneous statement or action related to the content of an ATC message between the pilots or between a pilot and the controller. For example, stating that the speed clearance is $250 \mathrm{kts}$., when the clearance content actually indicates $260 \mathrm{kts}$.

In order to explore NextGen and SESAR clearance characteristics, the impact of communication modality, 
message length, and temporal aspect upon communication inefficiency (clarification and errors) was analyzed. Of the total number of 920 messages sent to all crews in the simulation, $290(30 \%)$ messages had at least clarification associated with it, while $57(7 \%)$ of the messages had at least one communication error. It is important to note that these communication errors did not necessarily lead to an error in aircraft operation as a result of the ATC clearance instruction. The errors reflected in this study are indicative of errors made in communication only.

Using chi square analyses comparing voice and data link messages for the frequency of clarifications and errors, no significant differences were found for clarifications between the two modalities (Fig. 4). However, there was a significant difference for the number of communication errors $\left(\chi^{2}=6.42\right.$, $\mathrm{df}=1, \mathrm{p}<.05)$. There were more communication errors resulting from voice clearances than data link clearances.

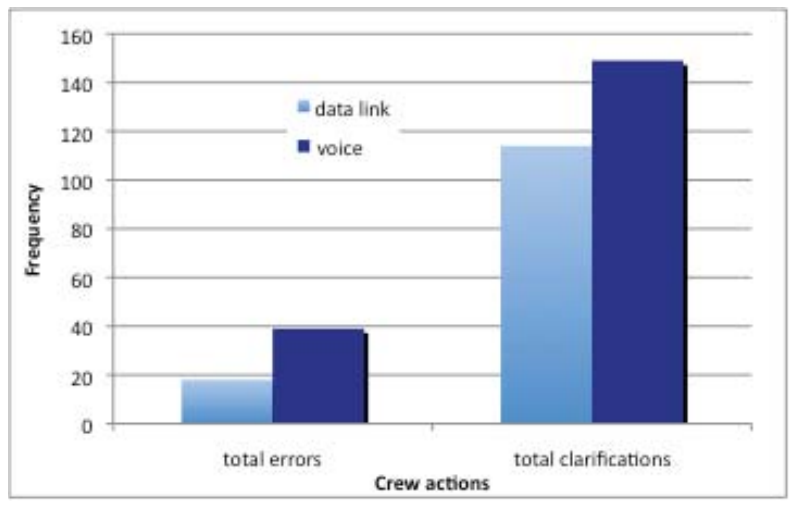

Figure 4. Number of errors and clarification by communication mode

A more detailed examination of the frequencies indicates that, although a greater number of errors occurred within crew as opposed to from air to ground, of these air to ground errors, the majority of them were made through the voice mode, and very few air ground errors were made through data link. Fig. 5 presents the number of communication errors and clarifications sorted by message modality and error and clarification type (within-crew or air-ground). These data reveal that most of the errors and clarifications are withincrew. However, within-crew, the number of errors and clarifications are very similar across the mode of the message (data link versus voice). Air to ground errors and clarifications are far more numerous if the original message was relayed by voice. There are relatively few errors and clarifications related to messages sent by data link.

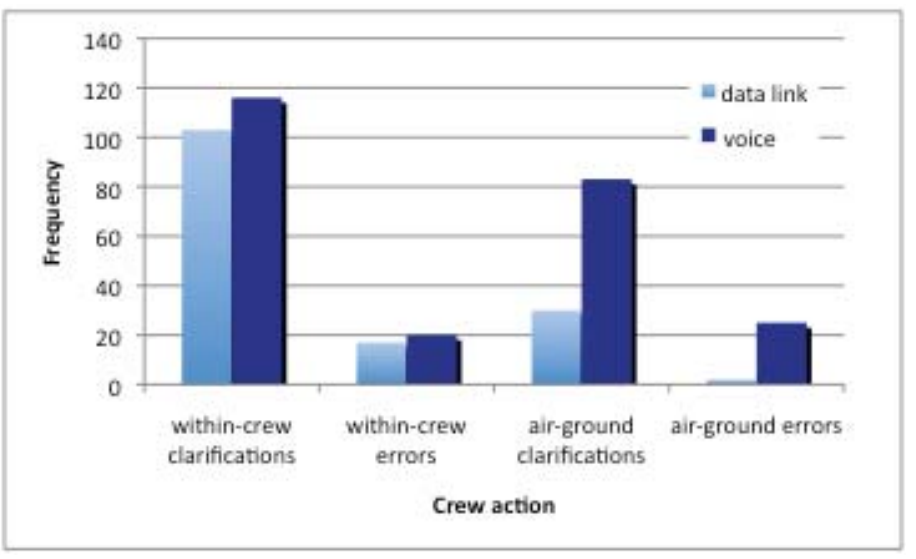

Figure 5. Number of within-crew and air-ground clarifications and errors by communication mode

The higher number of communication errors that were associated with the voice messages points to one of the principal benefits of digital communication; that is, the permanence of the data link clearance information. The data can remain on the display for as long as the crew needs the information, and a pilot can recall the message if necessary by accessing the message log. The ATC message in written form also mitigates voice message errors caused by mishearing, errors that are common in the existing voice environment [16]. The prevalence of air-ground errors in voice communication likely is a result of the fact that the crews were often conducting a readback to the controller as part of a voice message when the error was committed. Verbal responses to the controller are not required in data link communications. As previously noted, these are communication errors and do not reflect errors in data entry or clearance implementation.

The impact of the temporal aspect of the messages upon communications errors and clarifications was also evaluated for these simulation data. Of the ATC clearances of interest in this study, $50 \%$ ( 8 out of 16 ) of the messages were strategic and $50 \%$ of the messages were tactical. Strategic messages were conditional messages that contained at least one component to be completed at some point in the future, whereas the tactical messages contained only clearance instructions to be completed at the time of the message transmittal. An example of a conditional clearance was the following: "At BOLDR proceed direct CEDES, Cross BOLDR at and maintain 10,000 feet".

Chi-squire analysis of the communication clarifications and errors for clearances with and without conditional elements revealed significantly more clarifications and errors related to conditional clearances (errors: $\chi^{2}=15.24, \mathrm{df}=1$, $\mathrm{p}<.001$; clarifications: $\left.\chi^{2}=157.01, \mathrm{df}=1, \mathrm{p}<.001\right)$. 
Examination of the frequency of the errors and clarifications indicate a greater number of clarifications and errors occur when the message has a conditional element regardless of the type of error (both air-ground and within-crew errors and clarifications; see Figure 6). Communication modality did not appear to impact the (confusing) influence of conditional message elements. For conditional voice messages, there is also a large number of associated air-ground clarifications when compared to the data link conditional messages or messages without conditional elements. When receiving voice clearances, pilots are more likely to use the voice frequency to clear up message confusion directly with the controller rather than rely upon the their fellow crewmember.

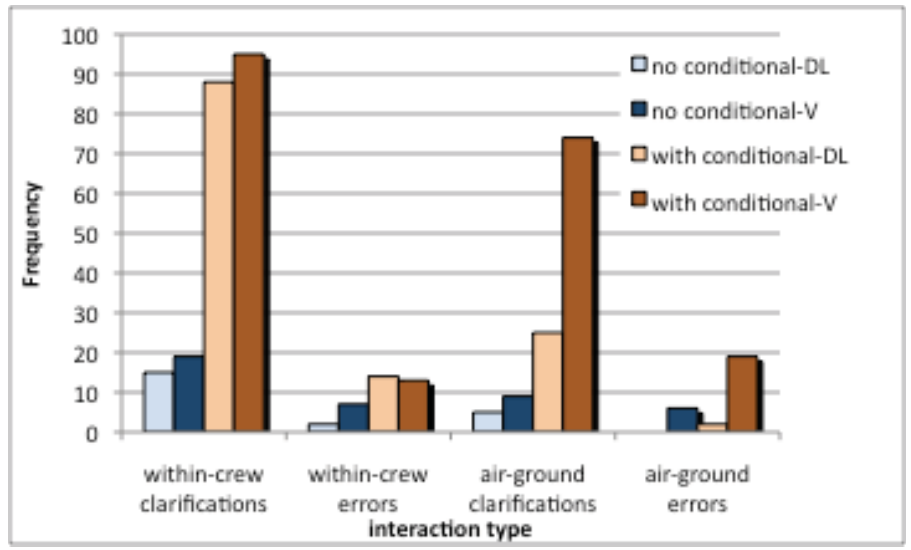

Figure 6. Number of clarifications and errors by conditionality of message, mode, and interaction type

Strategic clearances are expected to become more predominant in future ATM environments to reflect NextGen and SESAR operations. Strategic clearances, defined as conditional clearances in this investigation, were found to potentially decrease crew situation awareness as indicated by the increase of clarification comments concerning clearance information. The clarifications occurred in within-crew communication (between pilots) and air-ground communication (between the pilot and controller), and suggest confusion regarding the content of the ATC instructions. The impact of the conditional clearance with respect to changes upon the existing aircraft routing was often questioned, which indicates possible confusion about the impact of the conditional element upon the current ATC instruction. The future component in conditional clearances (e.g., "At BOLDR, reduce speed to 250 ") creates an additional temporal constraint that appears to add another layer of confusion regarding interpretation of the instruction. This temporal confusion is not directly related to memory constraints, so would not be alleviated by the permanent nature of data link.
Message length was also assessed with regard to communication errors and clarification. Longer messages are defined as messages with three elements (e.g., speed, altitude, route instruction), while short messages were messages with just one component. A chi-square analysis revealed significantly more communication errors and clarifications for longer messages compared to shorter messages (errors: $\chi^{2}=$ 10.29, $\mathrm{df}=1, \mathrm{p}<.01$; clarifications: $\left.\chi^{2}=105.42, \mathrm{df}=1, \mathrm{p}<.001\right)$.

Fig. 7 presents the data for these findings. Examination of the frequencies for errors and clarifications by message length and communication modality indicates that within crew communication clarifications occur more often if the original message was long. As with conditional clearances, there are more air-ground clarifications for long voice messages when compared to short messages or long data link messages. Voice clearances encourage the use of the voice modality to clarify message confusion.

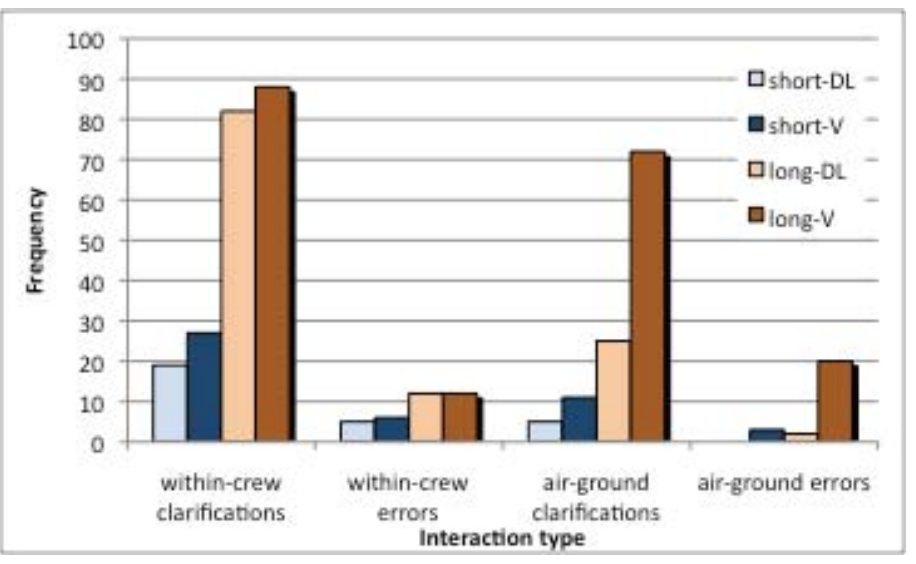

Figure 7. Number of clarifications and errors by length of message, mode, and interaction type

The trajectory-based operations promoted in the NextGen and SESAR concepts require a shift to more complex clearance data in air traffic management. This generally requires the use of clearance messages that have more data included, and are therefore longer. It is not surprising that this simulation found more clarifications associated with long messages (three operational elements) compared to short messages (one operational element). Previous research has found similar communication inefficiencies for long messages in the voice environment, and similar results in data link clearances $[9,17]$. Despite message permanence, longer data link messages have some of the same issues that exist in the voice environment: more data to perceive and evaluate for the pilot, introducing more opportunity for confusion. 


\section{Pilot Workload}

Pilot workload data were collected to evaluate the potential impact of the scenarios upon the pilot participants. The ATWIT procedure developed by Stein (Air Traffic Workload Input Technique) was used as a means to collect these data real-time during each of the six flight scenarios collected for each crew [18]. At four-minute intervals within the flight, each crewmember would press a button from one to seven on a keypad located within easy reach of the right seat and left seat. Participant pilots were instructed that " 1 " indicated very low workload and " 7 " indicated very high workload. During the scenario, the pilots were made aware of the four-minute data entry point by an aural indication (a chirp sound) and the illumination of the keys on the keypad.

Workload data for two of the twenty pilots (one of the ten crews) are missing due to a malfunction in the data collection tool. Fig. 8 presents the data for the Captains and First Officers for the remaining nine crews for all six scenarios. Noteworthy is the variability of average workload among the crewmembers. Crew 2 and Crew 6 both report their workload relatively high, above the midpoint score of four. The First Officer in Crew 5 rated his workload particularly high, with a mean of close to six. Crew Five, on the other hand, had mean ratings for the Captain and First Officer of close to two, a relatively low workload mean score.

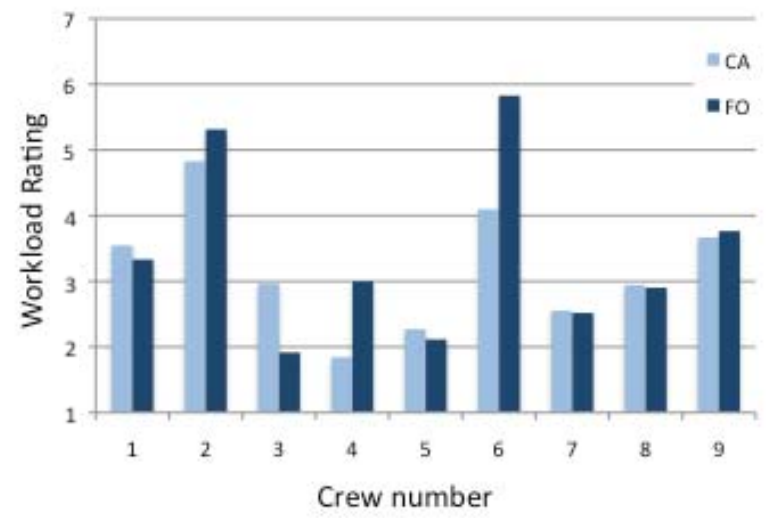

Figure 8. Mean workload ratings for all crews for all scenarios ( $7=$ very high, $1=$ very low)

The workload associated with ability to autoload clearance elements into the autoflight system was also analyzed. Fig. 9 shows the mean values of the workload ratings for the 18 Captains and First Officers for the autoload and manual load scenarios. Each crew flew three scenarios in which there were some clearances that had at least one clearance component that could be autoloaded. The remaining three scenarios flown required manual loading of those same clearances. There was very little difference between the Captains' and First Officers' rating for the workload of the autoload v. manual load scenarios. However, the manual load condition of the routes has higher means for workload ratings for both crewmembers, with the exception of the Oceanic Route. There is a significant difference both by route $(\mathrm{F}(2,142)=5.53, \mathrm{p}=.005)$ and by the loadability $(\mathrm{F}(1,142)=5.09, \mathrm{p}=.026)$ of the messages between Captains' ratings (CA) across the 9 crews (when tested using a univariate analysis of variance). There is also a significant interaction between route and loadability $(\mathrm{F}(2,142)$ $=4.83, \mathrm{p}=.009$ ). The Oceanic Route appears to have relatively low crew workload for the manual data entry condition, while the Big Sur Route appears to have relatively high workload for crewmembers for the manual entry condition.

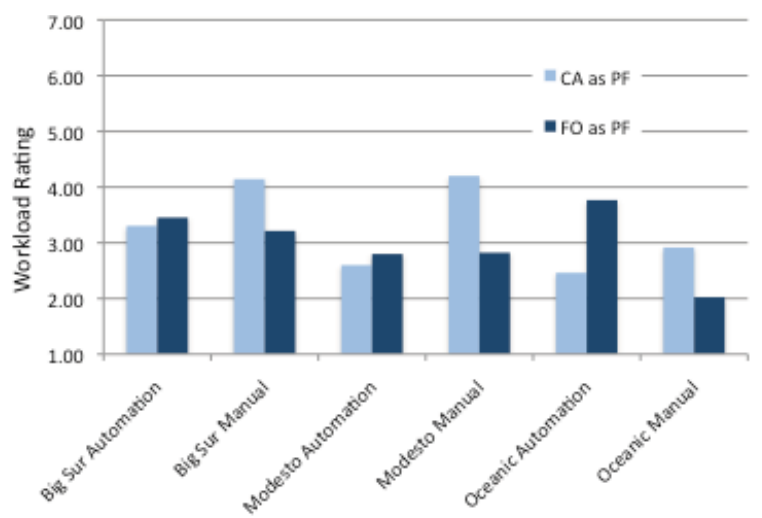

Figure 9 . Mean workload by route and autoload/manual load ability $(7=$ very high, 1 = very low)

It is unclear as to why this difference in the loading procedure exists. However, the relatively low workload means for the Oceanic Route may be associated with the fact that, compared to the other two routes, it took a few minutes longer to fly, and had more time between messages that resulted in less time pressure. Workload for the Big Sur Route may have increased because it contained a message that indicated that the expected landing runway had been closed, so the crew must switch to landing on Runway $28 \mathrm{~L}$.

Previous research indicates that the use of data link and voice clearances in the same airspace environment may create human performance concerns for pilots [9]. The mix and distribution of the experimental variables within each scenario (modality, message length, and message temporal quality) prevent any direct evaluation of the impact of these conditions upon workload. In general, however, this study revealed that the mix of data link and voice messages within the terminal environment did not create excessive workload.

In the debrief, all the pilots endorsed the autoload ability within data link, stating that it is a capability that they find beneficial for reducing data entry and heads down time despite 
the longer response times as shown in Figure 3. Previous studies have found similar acceptability with the autoload function [11]. Most of our participants also expressed the belief that it reduces data entry errors.

\section{CONCLUSION AND NEXT STEPS}

A human-in-the-loop simulation with commercial flight crews as participants was conducted to investigate the use of data link communications in the terminal area. Of particular interest in this study was an examination of more complex and longer messages that are expected as we transition to future ATM airspace environments.

As with a number of other flight deck simulations, this study found that data link communications resulted in longer clearance acknowledgment times than voice. However, the characteristics of data link, such as the reduction of frequency congestion and the ability to prioritize ATC communication tasks, may still allow for the use of this form of communication in the terminal area. The participant pilots did report that they found data link communications in the terminal area acceptable. The pilot acceptability of data link in the terminal area is similar to findings in other simulations [19].

As we continue to rely more upon the use of complex, long clearances in an attempt to shift to more trajectory-based clearances, new human performance issues will be introduced in the ATM environment. This investigation suggests that adding future components to ATC clearance messages may result in a reduction of flight crew awareness of clearance content. The communication confusion seems to involve the timing of the implementation of the instruction. Memory constraints associated with receiving a clearance prior to its execution may also exist. In NextGen and SESAR, the use of conditional clearances will become more predominant across all flight phases; thus, this concern may not be unique to the terminal area. Previous findings indicate that the use of conditional clearances contributed to confusion in the existing oceanic environment [20].

Despite the presence of long and complex ATC messages, the pilot workload in this simulation was found to be generally at a low to moderate level. Since all scenarios had a mix of voice and data link, as is expected in future operations, this is a result that represents the pilot experience in future ATM environments. Moreover, this workload finding corresponds with the pilot feedback indicating that the operations flown in the study were acceptable. The potential differences in autoload v. manual load for the routes may be a result of the operational implications of data entry and route modifications, such as a runway change.

Future work should address different flight deck data link implementations and flight crew procedures. The impact of conditional clearances, and other strategic clearance types, should be examined to insure that these clearances can be evaluated in a correct and timely manner to insure safety and efficiency in the future ATM systems.

\section{REFERENCES}

[1] K. Kerns (1999). Human factors in air traffic control/flight deck integration: Implications of data-link simulation research. In D. J. Garland, J. A. Wise \& V. D. Hopkin (Eds.), Handbook of aviation human factors (pp. 519-546). New Jersey: Lawrence Erlbaum Associates, Inc.

[2] Single European Sky ATM Research (SESAR): http://www.sesarju.eu/programme

[3] Next Generation Air Transportation System (NextGen): http://www.faa.gov/nextgen/

[4] R.D. Sorkin (1987). Design of auditory and tactile displays. In G. Salvendy (Ed.), Handbook of human factors. New York: Wiley-Interscience.

[5] E. Logsdon "An Examination of Data Link Autoload and Message Length”, Masters Dissertation, Psychology Department, San Jose State University, San Jose, CA, 1996

[6] M. Mackintosh, S. Lozito, A. McGann, \& E. Logsdon (1999) Designing Procedures for Controller-Pilot Data Link Communication: Effects of Textual Data Link on Information Transfer (SAE Tech. Paper 1999-01-5507). World Aviation Congress \& Exposition, October 19-21.

[7] S. Lozito, A. McGann, \& K. Corker (1993). Datalink ATC and Flight Deck Environment: Experiment in Flight Crew Performance. Proceedings of the 7th International Symposium of Aviation Psychology, (pp. 1009-1015). Ohio State University: Columbus, $\mathrm{OH}$.

[8] McGann, A., Lozito, S., \& Corker, K. (1993). Flight Deck Data Link Displays: An Evaluation of Textual and Graphical Implementations. International Journal of Aviation Psychology.

[9] A. McGann, D. Morrow, M. Rodvold, \& M. A. Mackintosh (1998). Mixed-Media Communication on the 
Flight deck: A Comparison of Voice, Data Link, and Mixed ATC Environments. International Journal of Aviation Psychology, 8(2), 137-156.

[10] K. Kerns (1991). Data-link communication between controllers and pilots: A review and synthesis of the simulation literature. The International Journal of Aviation Psychology, 1(3), 181-204.

[11] R. N. H.W. van Gent (1995). Human Factors Issues with Airborne Data Link; Towards Increased Crew Acceptance for Both En-Route and Terminal Flight Operations (NLRTP-95666). Amsterdam, The Netherlands: National Aerospace Laboratory NLR.

[12] Eurocontrol Services: http://www.eurocontrol.int/agdl

[13] J. Jakobi, B. Lorenz, \& M. Biella (2004). Evaluation of an Onboard Taxi Guidance System. In D.A. Vincenzi, M. Mouloua, \& P.A., Hancock (Eds.) Human Performance, Situation Awareness and Automation: Current Research and Trends (pp. 143-149), New York: Psychology Press.

[14] B. Hooey, D. Foyle, A Andre, K. Purcell \& S. Dowell (2000). Optimizing Airport Surface Operations Using Datalink and the Taxiway Navigation and Situation Awareness (T-NASA) Display Suite. Proceedings of the Human Factors and Ergonomics Society 44th Annual Meeting. Human Factors and Ergonomics Society: Santa Monica, CA.

[15] Sullivan, B. T. \& Soukup, P. A. (1996, July). The NASA 747-400 flight simulator: National resource for aviation safety research. Paper presented at American Institute of Aeronautics and Astronautics, San Diego, CA (AIAA-963517).

[16] RTCA Special Committee 214/Eurocae Working Group 78 Message Set (2012).

[17] K. Cardosi \& P. Boole (1991). Analysis of pilot response time to time-critical air traffic control calls (Rep. No. DOT/FAA/RD-91/20). Washington, DC: Department of Transportation, Federal Aviation Administration.

[18] E.S. Stein (1985). Air traffic controller workload: An examination of workload probe (DOT/FAA/CTTN84/24). Atlantic City Airport, NJ: Federal Aviation Administration Technical Center.

[19] R. Norman, B. Baxley, C. Adams, K. Ellis, K. Latorella, \& J. Comstock. (2010). NASA/FAA Data Comm Airside Human-in-the-Loop Simulation. Hampton, VA:
National Aeronautics and Space Administration, Langley Research Center

[20] J. Brown \& D. Castaño (2001). Human Factors issues in Controller-to-Pilot Data Link Communication. Focusing Attention on Aviation Safety, Proceedings of the 11th International Symposium on Aviation Psychology, Columbus, $\mathrm{OH}$.

\section{ACKNOWLEDGMENT}

This paper was funded by the NextGen Advanced Concepts and Technology Development Human Factors Division of the Federal Aviation Administration (ANG-C1). Special thanks to Dan Herschler and Tom McCloy for their guidance and expertise. Special thanks also to Kim Cardosi and Tracy Lennertz for their research expertise and wisdom. Finally, much appreciation to the Crew-Vehicle System Research Facility Staff at NASA Ames Research Center for their excellent simulator development skills, hard work, and patience.

\section{AUTHOR BIOGRAPHIES}

Lynne Martin is an ATM human factors researcher at the NASA Ames Research Center. Her research focus areas include human factors and human-automation interaction both in the flight deck and ATC domains.

Sandy Lozito has been an ATM human factors researcher at NASA Ames Researcher Center for over twenty years. Her research areas include human factors, automation, data link communications, and surface operations.

Vicki Dulchinos has a Master's Degree in Experimental Psychology from San Jose State University. Her research areas include data link communications, surface operations, and human factors.

John Kaneshige is a research engineer in the Intelligent Systems Division at NASA Ames Research Center. His research areas include intelligent control and flight management systems.

Shivanjli Sharma is a research engineer in the Intelligent Systems Division at NASA Ames Research Center. Her research areas include flight deck operations and flight management systems. She received her BS and MS in Aerospace Engineering from the University of California Davis. 